Provided for non-commercial research and education use. Not for reproduction, distribution or commercial use.

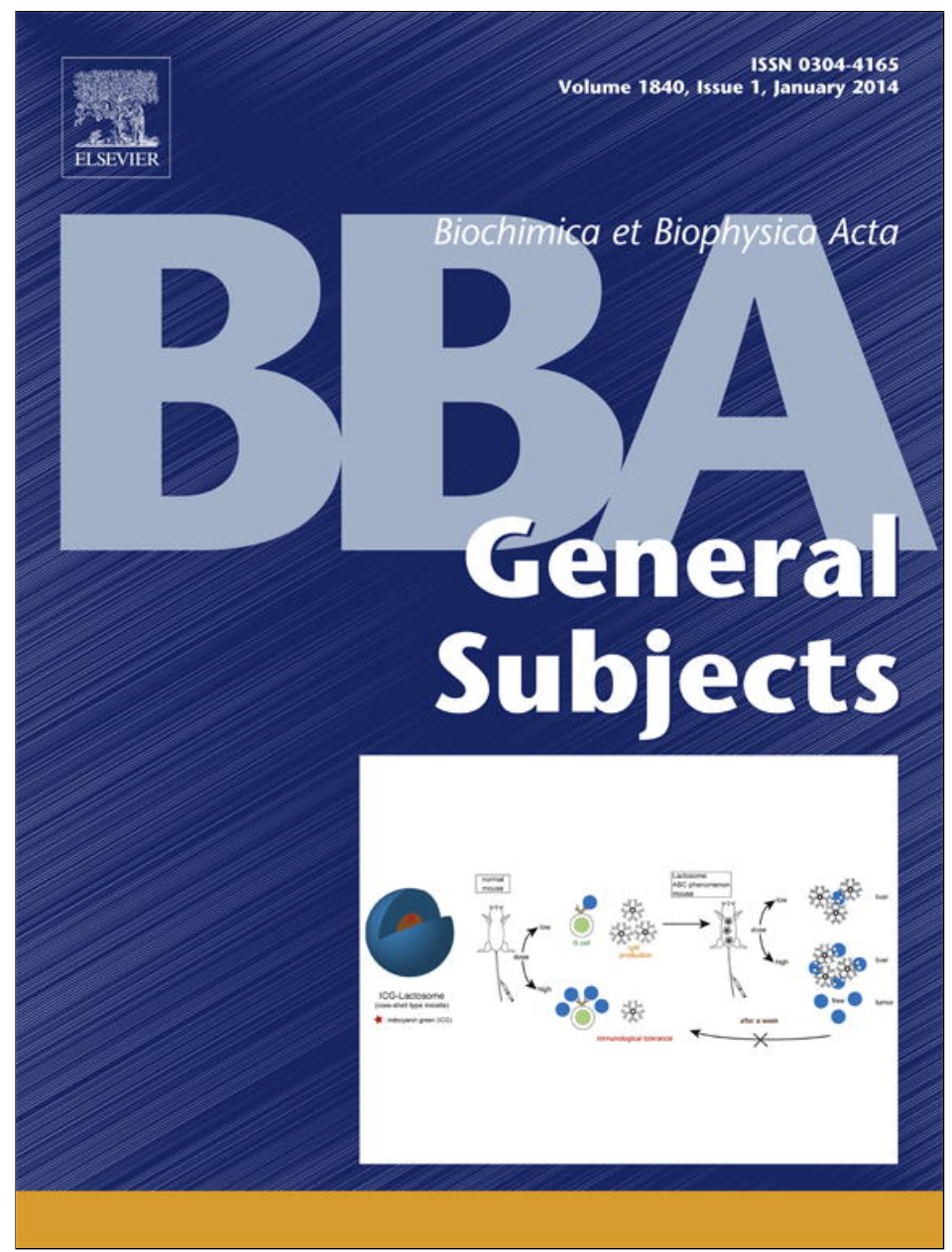

This article appeared in a journal published by Elsevier. The attached copy is furnished to the author for internal non-commercial research and education use, including for instruction at the authors institution and sharing with colleagues.

Other uses, including reproduction and distribution, or selling or licensing copies, or posting to personal, institutional or third party websites are prohibited.

In most cases authors are permitted to post their version of the article (e.g. in Word or Tex form) to their personal website or institutional repository. Authors requiring further information regarding Elsevier's archiving and manuscript policies are encouraged to visit:

http://www.elsevier.com/authorsrights 


\title{
The Salmonella enterica ZinT structure, zinc affinity and interaction with the high-affinity uptake protein ZnuA provide insight into the management of periplasmic zinc
}

\author{
Andrea Ilari a,1 ${ }^{\text {, Flaminia Alaleona }}{ }^{\mathrm{a}, 1}$, Giancarlo Tria ${ }^{\mathrm{c}, \mathrm{d}}$, Patrizia Petrarca ${ }^{\mathrm{b}, \mathrm{e}}$, Andrea Battistoni ${ }^{\mathrm{b}, \mathrm{e}}$, \\ Carlotta Zamparelli ${ }^{\text {a }}$, Daniela Verzili ${ }^{\text {a }}$, Mattia Falconi ${ }^{\text {b,e }}$, Emilia Chiancone ${ }^{\text {a,* }}$ \\ a CNR Institute of Molecular Biology and Pathology and Department of Biochemical Sciences, “Sapienza" University of Rome, Piazzale A. Moro 5, 00185 Rome, Italy \\ b Department of Biology, University of Rome "Tor Vergata" and CIBB, Center of Biostatistics and Bioinformatics, Via della Ricerca Scientifica, 00133 Rome, Italy

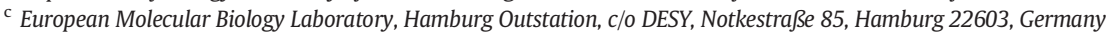 \\ d Centre for Bioinformatics, University of Hamburg, Bundesstrasse 43, D-20146 Hamburg, Germany \\ e Interuniversity Consortium, National Institute Biostructures and Biosystems (INBB), Rome, Italy
}

\section{A R T I C L E I N F O}

\section{Article history:}

Received 18 July 2013

Received in revised form 17 September 2013

Accepted 7 October 2013

Available online 12 October 2013

\section{Keywords:}

Salmonella enterica

Zinc transport

Zinc affinity

Protein-protein interaction

SAXS

Analytical ultracentrifugation

\begin{abstract}
A B S T R A C T
Background: In Gram-negative bacteria the ZnuABC transporter ensures adequate zinc import in $\mathrm{Zn}$ (II)-poor environments, like those encountered by pathogens within the infected host. Recently, the metal-binding protein ZinT was suggested to operate as an accessory component of ZnuABC in periplasmic zinc recruitment. Since ZinT is known to form a ZinT-ZnuA complex in the presence of $\mathrm{Zn}$ (II) it was proposed to transfer $\mathrm{Zn}$ (II) to $\mathrm{ZnuA}$. The present work was undertaken to test this claim.

Methods: ZinT and its structural relationship with ZnuA have been characterized by multiple biophysical techniques (X-ray crystallography, SAXS, analytical ultracentrifugation, fluorescence spectroscopy).

Results: The metal-free and metal-bound crystal structures of Salmonella enterica ZinT show one Zn(II) binding site and limited structural changes upon metal removal. Spectroscopic titrations with $\mathrm{Zn}$ (II) yield a $\mathrm{K}_{\mathrm{D}}$ value of $22 \pm 2 \mathrm{nM}$ for ZinT, while those with ZnuA point to one high affinity $\left(\mathrm{K}_{\mathrm{D}}<20 \mathrm{nM}\right)$ and one low affinity $\mathrm{Zn}$ (II) binding site ( $\mathrm{K}_{\mathrm{D}}$ in the micromolar range). Sedimentation velocity experiments established that $\mathrm{Zn}(\mathrm{II})$-bound ZinT interacts with ZnuA, whereas apo-ZinT does not. The model of the ZinT-ZnuA complex derived from small angle X-ray scattering experiments points to a disposition that favors metal transfer as the metal binding cavities of the two proteins face each other.

Conclusions: ZinT acts as a Zn(II)-buffering protein that delivers Zn(II) to ZnuA.

General significance: Knowledge of the ZinT-ZnuA relationship is crucial for understanding bacterial $\mathrm{Zn}$ (II) uptake.
\end{abstract}

(C) 2013 Elsevier B.V. All rights reserved.

\section{Introduction}

Zinc ( $\mathrm{Zn})$ is the second most abundant transition metal after iron in living organisms where it plays vital roles. In bacteria, $\mathrm{Zn}$ has a catalytic function in a large number of housekeeping enzymes or virulencerelated ones (e.g. $\beta$-lactamases or extracellular metalloproteinases) and a structural role in other enzymes (e.g. periplasmic copper, zinc superoxide dismutase). On the other hand, $\mathrm{Zn}$ at high concentrations is highly toxic for all cell types since it can interact non-specifically with polypeptide chains [1] and in that way inhibit essential enzymes [2]. It follows that the cellular concentration of $\mathrm{Zn}$, as well as that of other metals like iron, has to be controlled very strictly. Bacteria achieve the

\footnotetext{
* Corresponding author. Tel.: + 39064940543.

E-mail address: emilia.chiancone@uniroma1.it (E. Chiancone).

${ }^{1}$ The authors contributed equally to the work.
}

delicate balance between the requirement for $\mathrm{Zn}$ and its toxicity by the coordinated action of high- and low-affinity uptake systems and of export systems that rid the cells of excess $\mathrm{Zn}$. Thus, different transporters acquire the metal from the growth medium to reach a total concentration in the submillimolar range, while transcriptionally controlled zinc uptake and efflux systems maintain the readily exchangeable "free" zinc at very low concentrations [3]. Whereas initial in vitro studies suggested that cellular "free" zinc levels are in the femtomolar range [3], more recent studies involving ratiometric zinc biosensors have shown that the in vivo "free" zinc is around $20 \mathrm{pM}$ [4].

Investigations carried out on Escherichia coli, and confirmed for other microorganisms like Salmonella enterica, have established that the activity of the $\mathrm{Zn}$ import and export systems is controlled by Zur and ZntR, two metalloproteins that regulate gene transcription depending on their metallation state. Zur comes into play when the Zn concentration in the medium is low [5]; it is known to control the expression of the high affinity Zn uptake system ZnuABC, which is used by Gram- 
negative bacteria to transport $\mathrm{Zn}$ from the periplasmic space to the cytosol. ZnuABC is a high affinity ATP-binding cassette-type transporter and like all such systems is composed of three proteins: a soluble periplasmic component (ZnuA) that captures $\mathrm{Zn}(\mathrm{II})$ and delivers it to the membrane permease (ZnuB), whereas the ATPase component (ZnuC) provides the energy necessary for ion transport through the inner membrane.

Panina et al. [6] identified other Zur-regulated genes interspersed within the bacterial chromosome. These include the gene for a putative metal-binding protein named ZinT, categorized initially as a member of the E. coli cadmium stress stimulon [7]. ZinT was proposed to decrease the cadmium concentration in E. coli cells during cadmium stress. This putative function was ruled out by later studies which indicated clearly that ZinT is involved in Zn homeostasis [8-11]. In particular, Salmonella and $E$. coli strains deleted of the zinT gene were shown to be impaired in their ability to grow in media poor of this metal [10,11]; moreover, ZinT accumulation was shown to depend on zinc availability in the medium. As in the case of ZnuA, zint expression increases in bacteria growing in $\mathrm{Zn}$-poor media and is repressed in the presence of abundant $\mathrm{Zn}$. Importantly, the expression of zint is deregulated in bacteria lacking ZnuA, but not vice-versa. As a result, bacteria lacking the zint gene are able to grow in a medium with low zinc concentrations, despite the reduced duplication rates, whereas bacteria lacking the znua gene are unable to grow $[10,11]$. These results indicate that the $\operatorname{ZinT}$ and ZnuABC activities are strictly related and that ZinT may be considered an accessory member of the ZnuABC transporter. The tight linkage between ZinT and the ZnuA and ZnuB components of the transporter is evidenced also by other experimental data. Salmonella mutant strains deleted either of the whole znuABC operon or of the single $z n u A$ geneand thus potentially able to express ZnuB, but not ZnuA-are equally impaired in the ability to import environmental zinc [10]. It follows that ZnuB cannot mediate $\mathrm{Zn}(\mathrm{II})$ import in the absence of ZnuA. Further, ZinT cannot compensate for the lack of ZnuA, indicating that the role of ZinT is likewise dependent on the presence of ZnuA [10].

The data on the structural basis of this functional relationship are limited. It has been established that ZinT and ZnuA do not interact when metal-free, but form a stable complex when metal-bound [10]. However, the dependence of complex formation on the metallation state of the individual proteins and the mode of their interaction are not known. Interestingly, in some Gram-positive bacteria, $\mathrm{Zn}$ (II) transport is ensured by AdcA, a lipoprotein constructed by two domains resembling ZnuA and ZinT [6,12].

Even though several bacteria relying on the ZnuABC transporter to import $\mathrm{Zn}$ (II) do not possess ZinT, these studies suggest that the contribution of ZinT to metal recruitment within the periplasmic space is considerable, at least under conditions of severe $\mathrm{Zn}$ shortage and provided ZnuA is present [10]. It may be hypothesized that the ZinT contribution to $\mathrm{Zn}$ (II) recruitment entails binding of the metal with high affinity, followed by formation of a complex with ZnuA that allows metal to be transferred. To prove this contention, we have chosen to work on the proteins from S. enterica in view of the wealth of data accumulated in recent years on the ZnuABC transporter from this microorganism [10,13-15].

Firstly, X-ray crystal structure studies on S. enterica ZinT (SeZinT) in the metal-free and metal-bound forms were undertaken. The only ZinT structure known pertains to metal-bound E. coli ZinT (EcZinT, indicated originally as YodA) [16]. EcZinT is composed of two domains: a major one related structurally to the lipocalin/calycin protein family and a smaller helical domain. The metal-binding site, formed by histidine side chains, is buried at the domain interface, along the side of the calycin domain [16]. It was not established whether the binding of $\mathrm{Zn}$ (II) gives rise to protein conformational changes.

In contrast to the ZinT proteins, the X-ray structures of several members of the ZnuA family are known, namely those of the proteins from E. coli (EcZnuA, PDB codes: 2OGW; 2OSV; 2PRS) [17-19], Synechocystis 6803 (PDB code: 1PQ4) [20] and S. enterica (SeZnuA, PDB code: $2 \mathrm{XQV}$ ) [13]. The ZnuA family belongs to the so-called cluster 9 of periplasmic solute-binding proteins (PBPs) and displays their well conserved architecture comprising a pair of $(\alpha / \beta)_{4}$ sandwich domains and a connecting long, tightly packed $\alpha$-helix. The distinctive characteristic of all ZnuA proteins consists of a histidine rich (His-rich) loop located at the entrance of the $\mathrm{Zn}$ (II) binding site at the interface between the two domains. The SeZnuA structures with the Zn(II) binding site occupied either partially or fully, and the structure of a deletion mutant lacking a large part of the loop (SeZnuA $\Delta 118-141$ ), where the site is empty (PDB code: $2 \mathrm{XH}$ ), all indicate that the His-rich loop plays an important role in the $\mathrm{Zn}(\mathrm{II})$ management process. In fact, their comparison unveiled for the first time the occurrence of $\mathrm{Zn}$ (II)-induced conformational changes that are likely of functional relevance in metal sequestration from the periplasm and/or its delivery to ZnuB. In particular, His140, placed on the C-terminal part of the SeZnuA His-rich loop, appears of importance as it replaces His60 (EcZnuA numbering) [13], one of the otherwise conserved metal binding histidine residues in Zn- and Mn-specific PBPs. Moreover, structural-dynamical investigations pointed to a high mobility of the His-rich loop and suggested that the fluctuations may be influenced by $\mathrm{Zn}$ (II) binding either at the primary site or at the His-rich loop itself [14].

The hypothesis that the contribution of ZinT to the Zn(II) management processes in the $S$. enterica periplasm is based on its interaction with ZnuA and on the subsequent transfer of bound $\mathrm{Zn}(\mathrm{II})$ to the latter protein is strengthened by the data presented in this paper. Thus, the X-ray structures of metal-free and Zn(II)-bound SeZinT disclose Zn(II)-induced conformational changes that are confined to the area surrounding the $\mathrm{Zn}$ (II) binding site. An additional Zn(II)-bound SeZinT structure was solved that displays a PEG molecule in the inter-domain cleft, in a similar position as that occupied by the SeZnuA His-rich loop in the model of the SeZinT-Zn(II)-SeZnuA complex derived from SAXS experiments. In the modeled complex the $\mathrm{Zn}$ (II) binding sites of the two proteins face each other, in an arrangement that allows metal to be transferred. Significantly, SeZnuA has a higher affinity for the metal $\left(K_{D}<20 \mathrm{nM}\right)$ than SeZinT $\left(K_{\mathrm{D}} 22 \pm 2 \mathrm{nM}\right)$ and the interaction of ZinT with ZnuA takes place only when $\mathrm{Zn}(\mathrm{II})$ is bound to $\mathrm{ZinT}$.

\section{Material and methods}

\subsection{Protein purification}

Cells harboring plasmid pSEzinT [10] were grown at $37{ }^{\circ} \mathrm{C}$ in LB medium supplemented with $100 \mu \mathrm{g} / \mathrm{ml}$ ampicillin. Protein expression was induced overnight with $0.1 \mathrm{mM}$ isopropyl $\beta$-D-1thiogalattopiranoside (IPTG) when the absorbance of the culture at $600 \mathrm{~nm}$ reached 0.5 . Cells were harvested by centrifugation for $15 \mathrm{~min}$ at $5000 \mathrm{rpm}$ and periplasmic proteins were extracted by lysozyme treatment. Spheroplasts were separated from periplasmic proteins by centrifugation and the supernatant was applied to a NiNTA column pre-equilibrated with $50 \mathrm{mM} \mathrm{Na}$-phosphate, $250 \mathrm{mM} \mathrm{NaCl}$, pH 7.8 and eluted with a linear gradient of $0-500 \mathrm{mM}$ imidazole. ZinT eluted at $250 \mathrm{mM}$ imidazole, due to the presence of a naturally occurring His-rich N-terminal sequence which confers to the protein the ability to strongly interact with immobilized metal ions. Fractions containing ZinT (>98\% pure according to SDS-PAGE analyses) were pooled, dialyzed against $20 \mathrm{mM}$ HEPES, $10 \mathrm{mM} \mathrm{NaCl}, \mathrm{pH} 7.0$, concentrated to $20 \mathrm{mg} / \mathrm{ml}$ by ultrafiltration, using Amicon Ultrafiltration Discs YM-10, and stored at $-20^{\circ} \mathrm{C}$. About $20 \mathrm{mg}$ of purified protein was obtained per liter of bacterial culture. The protein concentration has been evaluated using the extinction coefficient at $280 \mathrm{~nm}\left(\varepsilon=37,485 \mathrm{M}^{-1} \mathrm{~cm}^{-1}\right)$ based on the protein amino acid composition (http://web.expasy. org/tools/protparam/protparam-doc.html). Wt SeZinT contains the signal peptide typical of periplasmic proteins and has 215 amino acids, whereas the recombinant protein comprises 186 residues. In the X-ray structure (see below) the first residues (HGHHAHGA) are not visible. 
SeZnuA and the metal-free protein were obtained as described by Petrarca et al. [10].

\subsection{Protein crystallization, data collection and data processing}

All SeZinT crystals were grown in about 2 weeks at $25{ }^{\circ} \mathrm{C}$ by the hanging-drop vapor diffusion method, using a protein sample concentrated to $\sim 20 \mathrm{mg} / \mathrm{ml}$. SeZinT crystals were obtained by mixing $1 \mu \mathrm{l}$ of protein sample with an equal amount of reservoir solution containing $2 \mathrm{M}$ ammonium sulfate and $0.1 \mathrm{M}$ sodium acetate, $\mathrm{pH}$ 5.0.

The Zn(II)-SeZinT and Zn(II)-SeZinT-PEG co-crystals were obtained upon addition of zinc acetate to a $20 \mathrm{mg} / \mathrm{ml}$ protein sample at an ion/ protein molar ratio of 5:1. The protein samples $(1 \mu \mathrm{l})$ were mixed with an equal amount of reservoir solution containing respectively $1.5 \mathrm{M}$ ammonium sulfate, $0.1 \mathrm{M}$ sodium acetate, $\mathrm{pH} 4.6$ or $0.22 \mathrm{M}$ ammonium sulfate, $0.1 \mathrm{M}$ sodium acetate, $\mathrm{pH} 4.6$ and 25\%-30\% PEG 4000. The crystals were cryo-protected in a solution containing $80 \%(\mathrm{v} / \mathrm{v})$ mother liquor and $20 \%(\mathrm{v} / \mathrm{v})$ glycerol. For transport to the synchrotron-radiation source and data collection, the crystals were mounted in nylon loops and flash frozen by quick submersion into liquid nitrogen. Three single-wavelength data sets $(\lambda=0.918 \AA)$ were collected from a SeZinT crystal and from co-crystals of Zn(II)-SeZinT and Zn(II)-SeZinT-PEG at the BL-14.1 beam-line of the Synchrotron Radiation Source BESSY (Berlin, Germany) [21], using a MAR Mosaic 225 CCD detector at $100 \mathrm{~K}$. The SeZinT and Zn(II)-SeZinT data sets were processed with DENZO [22] and scaled with SCALEPACK [22] while the Zn(II)-SeZinTPEG data set was processed with MOSFLM [23]. All the measured crystals belong to the P6122 space group. Crystal parameters and data collection statistics for the measured crystals are reported in Table 1.

\subsection{Solution and refinement of the X-ray structures}

All the structures were solved using EcZinT in complex with zinc (PDB entry: 1OEK) as search model. EcZinT displays 71.76\% sequence identity with SeZinT (calculated using the program CLUSTALW2 [24]). The rotational and translational searches, performed with the program

Table 1

Crystal parameters, data collection statistics and refinement statistics.

\begin{tabular}{|c|c|c|c|}
\hline & SeZinT & Zn(II)-SeZinT & $\mathrm{Zn}(\mathrm{II})-$ SeZinT-PEG \\
\hline \multicolumn{4}{|l|}{ Data collection } \\
\hline PDB code & 4arh & 4ayh & 4aw8 \\
\hline Space group & P6122 & P6122 & P6122 \\
\hline \multirow[t]{4}{*}{ Unit cell parameters } & $\mathrm{a}=58.53 \AA$ & $\mathrm{a}=58.40 \AA$ & $\mathrm{a}=58.54 \AA$ \\
\hline & $\mathrm{b}=58.53 \AA$ & $\mathrm{b}=58.40 \AA$ & $\mathrm{b}=58.54 \AA$ \\
\hline & $c=289.32 \AA$ & $c=291.47 \AA$ & $c=290.37 \AA$ \\
\hline & $\gamma=120^{\circ}$ & $\gamma=120^{\circ}$ & $\gamma=120^{\circ}$ \\
\hline Resolution shell $(\AA)$ & $\begin{array}{l}2.3-50.00 \\
(2.30-2.38)\end{array}$ & $2.5-99(2.5-2.59)$ & $\begin{array}{l}2.00-50.70 \\
(2.00-2.11)\end{array}$ \\
\hline$* \mathrm{R}_{\text {merge }}(\%)$ & $11.2(23.7)$ & $18.3(46.8)$ & $10(23.7)$ \\
\hline $\mathrm{I} / \sigma(\mathrm{I})$ & $25.62(14.75)$ & $15.2(3.83)$ & $16.30(8.90)$ \\
\hline Unique reflections & 14,007 & 10,654 & 21,245 \\
\hline Completeness (\%) & $99.1(99.9)$ & $97.9(100)$ & $100(100)$ \\
\hline Redundancy & $12.7(14.3)$ & $5.8(7)$ & $11(10.2)$ \\
\hline \multicolumn{4}{|l|}{ Refinement statistics } \\
\hline $\mathrm{R}_{\text {factor }}(\%)$ & 22.05 & 23.38 & 21.24 \\
\hline $\mathrm{R}_{\text {free }}(\%)$ & 28.84 & 32.2 & 25.69 \\
\hline FOM & 0.79 & 0.77 & 0.84 \\
\hline RMS bonds & 0.012 & 0.018 & 0.011 \\
\hline RMS angles & 1.284 & 1.611 & 1.244 \\
\hline \multicolumn{4}{|c|}{ Ramachandran analysis } \\
\hline \multicolumn{4}{|c|}{ Number of residues in: } \\
\hline Favored region & $178(96.7 \%)$ & $179(97.3 \%)$ & 177 (96.2\%) \\
\hline Allowed region & $6(3.3 \%)$ & $5(2.7 \%)$ & $7(3.8 \%)$ \\
\hline Outliers & $0(0.0) \%$ & $0(0.0) \%$ & $0(0.0) \%$ \\
\hline
\end{tabular}

Values in parentheses are for the highest-resolution.

$\mathrm{R}_{\text {merge }}=\sum_{\text {hkl }} \sum_{\mathrm{i}}\left|\mathrm{I}_{\mathrm{i}}(\mathrm{hkl})-\mathrm{I}(\mathrm{hkl})\right| / \sum_{\mathrm{hkl}} \sum_{\mathrm{i}_{\mathrm{i}}}(\mathrm{hkl})$, where $\mathrm{I}_{\mathrm{i}}(\mathrm{hkl})$ is the ith observation of the reflection (hkl) and $\mathrm{I}(\mathrm{hkl})$ is the mean intensity of the (hkl) reflection.
MOLREP [25], CCP4 suite [26] in the resolution range 3.0-10.0 A,, produced clear solutions, corresponding to one monomer in the asymmetric unit. Refinements were performed using the maximum likelihood method with the program REFMAC [27] and model building with the program COOT [28]. The refinement statistics are reported in Table 1 . The quality of the models was assessed using the program PROCHECK [29].

The final SeZinT model consists of 186 residues, 136 water molecules, and 6 sulfate ions. The model has been refined to an $\mathrm{R}_{\text {crys }}$ of $22.05 \%$ and an $\mathrm{R}_{\text {free }}$ of $28.84 \%$. The final Zn(II)-SeZinT model consists of 186 residues, 77 water molecules, 4 sulfate ions and 1 zinc ion. The model has been refined to an $\mathrm{R}_{\text {crys }}$ of $23.38 \%$ and an $\mathrm{R}_{\text {free }}$ of $32.20 \%$. The final $\mathrm{Zn}$ (II)-SeZinT-PEG model consists of 186 residues, 150 water molecules, 5 sulfate ions, 1 zinc ion, and 1 PEG molecule $\left(\mathrm{C}_{12} \mathrm{H}_{26} \mathrm{O}_{7}\right)$. The final $\mathrm{R}_{\text {crys }}$ is $21.24 \%$ and $\mathrm{R}_{\text {free }}$ is $25.69 \%$.

\subsection{Determination of the SeZinT and SeZnuA affinities for Zn(II)}

Binding of $\mathrm{Zn}$ (II) to SeZinT was followed by measuring the intrinsic protein fluorescence on a Fluoromax-4 spectrofluorometer (HoribaJobin Yvon). Fluorescence spectra were collected at $25^{\circ} \mathrm{C}$ using $1 \mathrm{~cm}$ path length cell, under continuous stirring. The excitation wavelength was $280 \mathrm{~nm}$, and emission was recorded between 300 and $450 \mathrm{~nm}$. ZinT was equilibrated with $20 \mathrm{mM}$ HEPES, $10 \mathrm{mM} \mathrm{NaCl}$, pH 7.5 treated previously with Chelex 100 to avoid metal contamination. ICP-MS analysis confirmed that the SeZinT:Zn molar ratio was $<0.01$. The same buffer was used to dilute the protein solution to a final concentration of $5 \mu \mathrm{M}$. A stock solution of zinc was prepared from atomic absorption standard (Fluka) diluted with ultra-pure water (Fluka). The metal was added to the protein in $0.15 \mu \mathrm{M}$ increments.

Zinc binding to SeZnuA was followed in indirect titration experiments in the presence of the indicator Mag-Fura-2, MF (Invitrogen) essentially as described in [19]. Absorption spectra were collected on a HewlettPackard diode array spectrophotometer at $25^{\circ} \mathrm{C}$. Freshly prepared MF was added to a solution of $20 \mathrm{mM}$ HEPES, $10 \mathrm{mM} \mathrm{NaCl}$, pH 7.5 to reach a final concentration of $16 \mu \mathrm{M}$ and a reference spectrum was collected. The absorbance maximum of MF occurs at $366 \mathrm{~nm}$, with an extinction coefficient of $29,900 \mathrm{M}^{-1} \mathrm{~cm}^{-1}$. When MF is bound to $\mathrm{Zn}(\mathrm{II})$ the absorbance maximum is shifted to the blue $(325 \mathrm{~nm})$ and the extinction coefficient at $366 \mathrm{~nm}$ decreases to $1880 \mathrm{M}^{-1} \mathrm{~cm}^{-1}$ [30]. The dissociation constant of zinc from MF, $\mathrm{K}_{\mathrm{D}}$, is $20 \mathrm{nM}$ at $\mathrm{pH} 7.0$ [31]. SeZnuA was added to the MF containing buffer at a final concentration of $20 \mu \mathrm{M}$; the aliquots of the $\mathrm{Zn}$ (II) stock solution described above were from 1 to $25 \mu \mathrm{M}$.

The overall $\mathrm{Zn}$ (II) dissociation constant, $\mathrm{K}_{\mathrm{D}}$, was obtained by fitting the experimental data obtained for both SeZinT and SeZnuA with a program written with Matlab (The Math Works, Natick, MA).

\subsection{Analytical ultracentrifugation}

Sedimentation velocity experiments were carried out on a Beckman Optima XL-I analytical ultracentrifuge using absorbance optics. Experiments were conducted at $30,000 \mathrm{rpm}$ and $20^{\circ} \mathrm{C}$. Radial absorbance scans were obtained in a continuous scan mode at $280 \mathrm{~nm}$ at a spacing of $0.003 \mathrm{~cm}$; three scans were averaged. Sedimentation coefficients were calculated using the program Sedfit (provided by P. Schuck, National Institutes of Health) and were reduced to water and $20{ }^{\circ} \mathrm{C}\left(\mathrm{s}_{20, \mathrm{w}}\right)$ using standard procedures. The samples were diluted in $20 \mathrm{mM}$ HEPES, $10 \mathrm{mM} \mathrm{NaCl}$, pH 7.5 to reach an absorbance at $280 \mathrm{~nm}$ of $0.6 \mathrm{AU}$ in a $1.2 \mathrm{~cm}$ optical path cell. When required, SeZinT $(22.2 \mathrm{kDa})$ and SeZnuA $(31.5 \mathrm{kDa})$ were mixed in a $1: 1$ molar ratio either in the apo- or in the holo-, $\mathrm{Zn}(\mathrm{II})$-bound form.

\subsection{Small angle $X$-ray scattering}

Synchrotron X-ray scattering data were collected at the beamline BM29 (ESRF, Grenoble) [32] using a robot sample changer [33]. The 
SeZnuA-SeZinT complex was measured at several concentrations ranging from 0.17 to $5.0 \mathrm{mg} / \mathrm{ml}$ in a HEPES buffer $20 \mathrm{mM}, 10 \mathrm{mM} \mathrm{NaCl}$, $\mathrm{pH}=7.5$. SAXS data were recorded at $4{ }^{\circ} \mathrm{C}$ using a Pilatus $1 \mathrm{M}$ pixel detector (DECTRIS, Baden, Switzerland) at a sample detector distance of $2.43 \mathrm{~m}$, covering the range of momentum transfer $0.005<\mathrm{s}<0.45 \AA^{-1}$ $(s=4 \pi \sin (\theta) / \lambda$ where $2 \theta$ is the scattering angle and $\lambda=0.931 \AA$ is the X-ray wavelength). To assess radiation damage, ten successive $1 \mathrm{~s}$ exposures of complex solutions were compared and no significant changes were observed (data not shown). The forward scattering $I(0)$ as well as the radius of gyration $\left(R_{g}\right)$ were calculated using the Guinier approximation [34] implemented in PRIMUS [35,36] and assuming that at very small angles $\left(s<1.3 / R_{g}\right)$ the intensity is represented as $I(s)=I(0) \cdot \exp \left(-\left(s R_{g}\right)^{2} / 3\right)$. The pair-distance distribution function $P(r)$, from which the maximum particle dimension $\left(D_{\max }\right)$ as well as $R_{g}$ were estimated, was computed using GNOM [37]. The molecular mass $(M M)$ was estimated from: (1) the Porod invariant [38] as 0.5 times the Porod volume for roughly globular particles [36], (2) the excluded volume of averaged hydrated particles computed using DAMAVER [39], and (3) the comparison of the forward scattering $I(0)$ with that of the well characterized bovine serum albumin $(\mathrm{BSA})\left(M M_{\mathrm{BSA}}=66 \mathrm{kDa}, I(0)_{\mathrm{BSA}}=69.184\right)[40]$. Ab initio models using low resolution data in the range of $0.012 \AA^{-1}<\mathrm{s}<0.22 \AA^{-1}$ were created using DAMMIF [41]. The tool constructs bead models keeping beads interconnected and the model compact while yielding a scattering profile with the lowest possible discrepancy $(\chi)$ to the experimental data

$\chi^{2}=\frac{1}{N-1} \sum_{j=1}^{N}\left[\frac{I_{\exp }\left(s_{j}\right)-c I_{\text {calc }}\left(s_{j}\right)}{\sigma\left(s_{j}\right)}\right]^{2}$

where $N$ is the number of experimental points, $c$ is a scaling factor and $I_{\text {calc }}\left(s_{j}\right)$ and $\sigma\left(s_{j}\right)$ are respectively the calculated intensity and the experimental error at the momentum transfer $s_{j}$. Twelve independent $a b$ initio reconstructions were performed and then averaged using DAMAVER [39], which also provides a value of normalized spatial discrepancy (NSD) representing a measure of similarity among different models (for ideally superimposed similar objects, NSD tends to 0 ; it exceeds 1 if the objects differ systematically from one another). Rigid body modeling was performed using MASSHA [42]. The tool allows one to display and manipulate atomic structures and low resolution models minimizing the discrepancy value $\chi$ (formula (1)) against the experimental data. Lastly, the program BUNCH [43] was used to model the missing loop as a chain of dummy residues that are separated by $3.8 \AA$ (to mimic a $\mathrm{C}_{\alpha}$ chain). The theoretical scattering curve was computed by CRYSOL [44] and the final model super-imposed on the $a b$ initio model using the program SUPCOMB [45]. All programs used for SAXS data analysis belong to the ATSAS package [36].

\section{Results}

\subsection{SeZinT: structural analysis}

Three different crystal structures were solved pertaining to SeZinT as purified (at $2.3 \AA$ resolution, PDB code: 4 ARH), zinc bound SeZinT (Zn(II)-SeZinT, at $2.5 \AA$ resolution, PDB code: $4 A Y H$ ) and zinc bound SeZinT containing a PEG molecule (Zn(II)-SeZinT-PEG, at 2.0 ̊̊ resolution, PDB code: $2 \mathrm{AW} 8)$; all structures are hexagonal $\left(\mathrm{P}_{1} 22\right)$ and contain one molecule in the asymmetric unit.

The analysis of the three SeZinT structures and their comparison with the EcZinT (YodA) one brings out the following points:

i) The overall fold of SeZinT resembles closely the EcZinT one, as expected in view of the high sequence identity $(71.76 \%$, Fig. 1A). It consists of the calyx domain - an antiparallel up- down $\beta$-barrel - and a smaller helical domain. Specifically, the $\mathrm{C} \alpha$ traces of SeZinT and EcZinT with $\mathrm{Ni}$ (II) bound to the $\mathrm{Zn}$ (II) binding site (PDB code: 1OEJ) [16] are almost super-imposable. The root-mean square deviation (rmsd) is $0.375 \AA$ (Fig. 1B) despite the occurrence of differences in the flexible parts, especially in the 128-135 loop (Fig. 1C). The His-rich N-terminal tail - HGHHAHG is not visible, pointing to its high flexibility, as in all the ZinT structures solved thus far. In particular, the average B factor of the last three visible residues $(8-10)$ is much higher than that calculated over the whole structure, e.g. $>45 \AA^{2}$ as compared to $27 \AA^{2}$ for Zn(II)-SeZinT.

ii) SeZinT as purified does not contain $\mathrm{Zn}$ (II) and hence represents the first metal-free ZinT structure available. In Zn(II)-SeZinT, only one $\mathrm{Zn}$ (II) is bound at the end of a hydrophobic pocket at the interface between the calyx and the helix domain (Fig. 1D), namely in the same position as cadmium, nickel and zinc in EcZinT (PDB codes: 1OEE, 1OEJ, 1OEK and 1S7D, respectively) [16].

$\mathrm{Zn}$ (II) binding gives rise to limited conformational changes as apparent from the superimpositions of the Zn(II)-SeZinT and $\mathrm{Zn}(\mathrm{II})$-SeZinT-PEG C $\alpha$ traces with that of SeZinT (rmsd of $0.248 \AA$ and $0.237 \AA$, respectively). The flexible $128-135$ loop is the only region which displays different conformations in the three structures. However, limited movements are apparent also in the $\mathrm{Zn}(\mathrm{II})$ binding site of $\mathrm{Zn}$ (II)-SeZinT where the metal is coordinated by His153 (NE2-Zn(II) distance of $2.19 \AA$ ), His155 (NE2-Zn(II) distance of $2.41 \AA$ ), His144 (NE2-Zn(II) distance of $2.93 \AA$ ) and a water molecule (O-Zn(II) distance of $2.96 \AA)$. As shown in Fig. 2A, His155 and His153, the two histidine residues placed at a canonical ligation distance from the metal, undergo a small movement; in particular His153 shifts by $1.9 \AA$ toward $\mathrm{Zn}$ (II). In Zn(II)-ZinT-PEG (Fig. 2B), the metal appears to be coordinated tetrahedrally by His153 (NE2-Zn(II) distance of $2.73 \AA$ ), His155 (NE2-Zn(II) distance of $2.60 \AA$ ), His144 (NE2$\mathrm{Zn}$ (II) distance of $2.48 \AA$ ) and an oxygen of the PEG molecule (O-Zn(II) distance of $2.55 \AA$ ). No conformational changes are apparent relative to the metal-free structure.

To allow a detailed comparison of the metal coordination shell in SeZinT and EcZinT, a description of the metal binding site in EcZinT is in order. Two $\mathrm{Zn}(\mathrm{II})$ are present in the 1OEK and 1S7D structures, in which one metal ion is coordinated by His144 and His155, whereas the other interacts with His153, His193, and the carboxyl moiety of Glu189. Several water molecules lie in close contact with the zinc ions, but no precise description of the coordination geometry is given due to local disorder. In the cadmium bound structure (PDB code: 1OEE), the metal is coordinated by three histidine side chains (His144, His153, and His155, from strands $F$ and $G$ of the calyx domain) and three water molecules in a typical octahedral geometry. In the nickel bound form of EcZinT (PDB code: 1OEJ), the metal is bound to His144, His153, and His155 like Cd(II). All the solved EcZinT structures also contain metal bound to the protein surface. Whereas the metal coordination shell and the position of bound $\mathrm{Zn}(\mathrm{II})$ in SeZinT resemble those of $\mathrm{Ni}(\mathrm{II})$, and $\mathrm{Cd}(\mathrm{II})$ bound to EcZinT (Fig. 2C), the mode of $\mathrm{Zn}$ (II) binding differs in the two proteins (Fig. 2D). In the EcZinT structure, two $\mathrm{Zn}$ (II) are placed in the canonical binding pocket as just described, most likely because the crystals were obtained at $200 \mathrm{mM}$ [16], a very high concentration as compared to $5 \mathrm{mM} \mathrm{Zn}$ (II) used to grow the $\mathrm{Zn}(\mathrm{II})$-SeZinT crystals and to the sub-millimolar concentrations typical of physiological conditions. As shown below, fluorescence titrations of SeZinT with $\mathrm{Zn}(\mathrm{II})$ provide evidence that the protein binds only one $\mathrm{Zn}$ (II) with high affinity.

iii) Surprisingly, in the Zn(II)-SeZinT-PEG crystal, a PEG molecule is present in the cavity between the calyx and the helical domain, that is lined with hydrophobic residues like Phe157 and Trp173 (Fig. 3). Two different PEG conformations (A and B), each with 
A

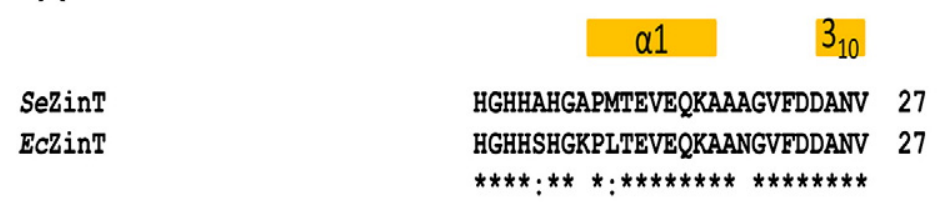

SeZinT RDRALTDWDGMWQSVYPYLVSGELDPVFRQKAKKDPEKTFEDIKAYYRKG 77 ECZinT QNRTLSDWDGVWQSVYPLLQSGKLDPVFQKKADADKTKTFAEIKDYYRKG 77

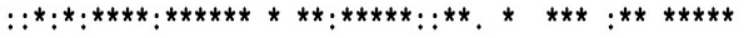

SeZinT

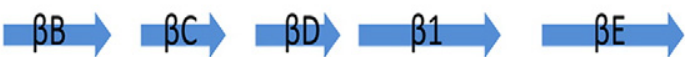

EcZinT YVTNVETIGIENGVIEFHRDNNVASCKYNYAGYKILTYASGKKGVRYLFE 127 YVTDIEMIGIEDGIVEFHRNNETTSCKYDYDGYKILTYKSGKKGVRYLFE 127

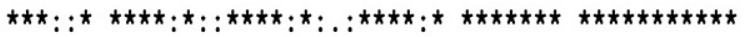

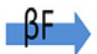

SeZinT CKDANSKAPKYVQFSDHIIAPRKSAHFHIFMGNTSQQALLQEMENWPTYY 177 EcZinT CKDPESKAPKYIQFSDHIIAPRKSSHFHIFMGNDSQQSLLNEMENWPTYY 177
$* * * .: * * * * * *: * * * * * * * * * * * *: * * * * * * * * * * *: * *: * * * * * * * * *$ $a 6$

SeZinT PYOLKANEVVDEMLHH 193 ECZinT PYQLSSEEVVEEMMSH 193 $* * * * .:: * * *: * *: *$
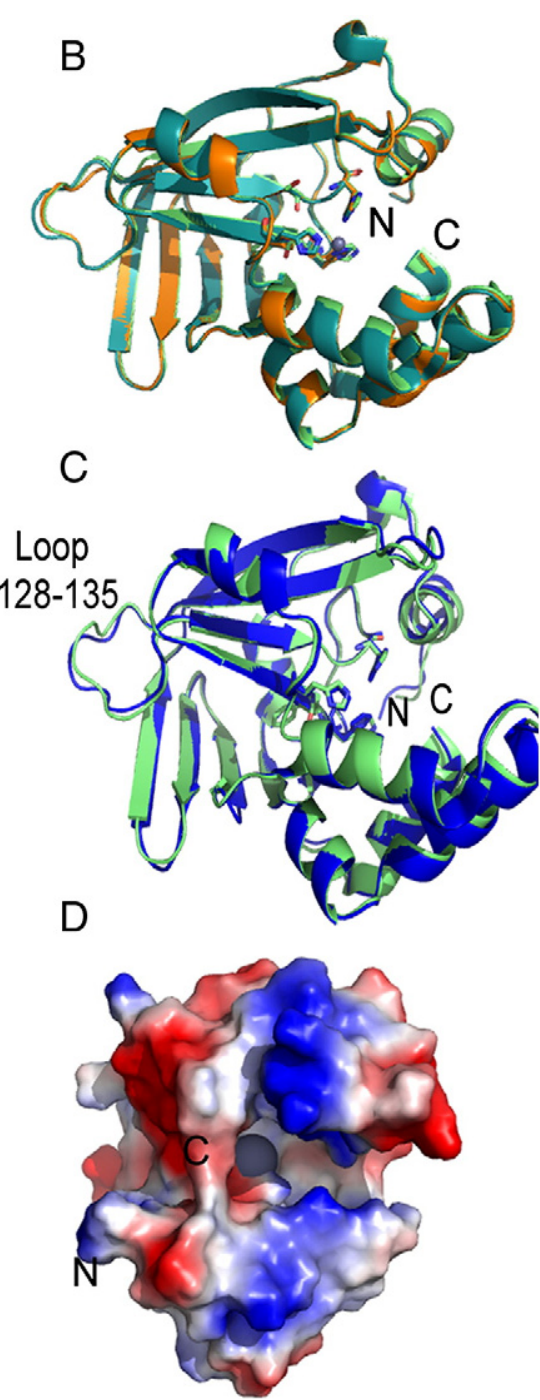

Fig. 1. Structural features of S. enterica ZinT. In (A), sequence alignment of EcZinT and SeZinT. The secondary structure elements are indicated. The Zn(II) coordinating residues are underlined. Identical residues are indicated by asterisks, those defined as similar and more similar by the ClustalW2 program [23] are indicated by '.' and by ':', respectively. In (B), overall fold. SeZinT (PDB code: 4ARH) is colored green, Zn(II)-SeZinT (PDB code: 4AYH) orange, and Zn(II)-SeZinT-PEG (PDB code: 4AW8) blue marine. The zinc ions and the coordinating histidines are indicated. In (C), superimposition between SeZinT and native EcZinT (PDB code: 1OEJ). SeZinT is colored green and EcZinT blue. In (D), electrostatic surface of Zn(II)-SeZinT, the bound zinc is represented as a gray sphere. The figures were prepared using PyMol [49].

0.5 occupancy, could be modeled in the protein cavity as the PEG molecule is not bound tightly to the protein. The A conformation is more stable due to binding of PEG to the zinc ion (O8$\mathrm{Zn}(\mathrm{II})=2.55 \AA$ ) and to formation of a hydrogen bond with Tyr115 $(\mathrm{OH}-014=3.1 \AA)$. In the B conformation the PEG molecule is hydrogen bonded only to His 144 , one of the zinc ligands. It may be surmised that the presence of the long and hydrophobic PEG molecule in the cavity between the two SeZinT domains mimics the SeZnuA His-rich loop in the SeZinT-SeZnuA complex (see below).

\subsection{Zinc affinity}

The affinity of SeZinT for Zn(II) was assessed by means of fluorescence titrations since Trp173, one of the three Trp residues, is located near the zinc binding site in the crystal structure. Indeed, the intrinsic protein fluorescence $\left(\lambda_{\max } 340 \mathrm{~nm}\right.$ ) increases as a function of added $\mathrm{Zn}$ (II). Consistent with the structural data, the normalized SeZinT fluorescence intensity measured in $20 \mathrm{mM}$ HEPES, $10 \mathrm{mM} \mathrm{NaCl}, \mathrm{pH} 7.5$, plotted as a function of added $\mathrm{Zn}(\mathrm{II})$, points to binding of one $\mathrm{Zn}(\mathrm{II}) /$ molecule (Fig. 4A). A very low dissociation constant $(22 \pm 2 \mathrm{nM})$ indicative of high affinity binding $\left(\mathrm{K}_{\mathrm{A}}=4.5 \times 10^{7} \mathrm{M}^{-1}\right)$ was obtained by fitting these data with the equation:

$$
\mathrm{C}=0.5\left(\mathrm{C}_{0}-\mathrm{L}_{\mathrm{T}}-\mathrm{K}_{\mathrm{D}}\right)+0.5\left(\left(\mathrm{C}_{0}-\mathrm{L}_{\mathrm{T}}-\mathrm{K}_{\mathrm{D}}\right)^{2}+4 \mathrm{~K}_{\mathrm{D}} \mathrm{C}_{0}\right)^{0.5}
$$

where $C$ is the concentration of metal-free $\mathrm{ZinT}, \mathrm{C}_{0}$ is the total protein concentration, $\mathrm{L}_{\mathrm{T}}$ is the total zinc concentration and $\mathrm{K}_{\mathrm{D}}$ is the dissociation constant of the ion from the protein.

The affinity of SeZnuA for Zn(II) was determined as well given the paucity of available information. Since the protein intrinsic fluorescence does not change upon addition of $\mathrm{Zn}$ (II), an indirect titration method in the presence of the indicator MF was employed [19]. The decrease in absorbance of the indicator was followed as a function of added $\mathrm{Zn}$ (II) at $366 \mathrm{~nm}$. The titration curve (Fig. 4B) displays an initial region of constant absorbance until about one equivalent of $\mathrm{Zn}(\mathrm{II}) / \mathrm{SeZnuA}$ is added, and thus indicates that SeZnuA outcompetes MF for available $\mathrm{Zn}(\mathrm{II})$. With increase in concentration of added $\mathrm{Zn}(\mathrm{II})$, the $366 \mathrm{~nm}$ absorbance decreases with a sigmoidal shape characterized by an inflection point at about $45 \mu \mathrm{M}$ added $\mathrm{Zn}(\mathrm{II})$. One can infer that SeZnuA possesses one $\mathrm{Zn}$ (II) binding site endowed with a higher affinity for the 

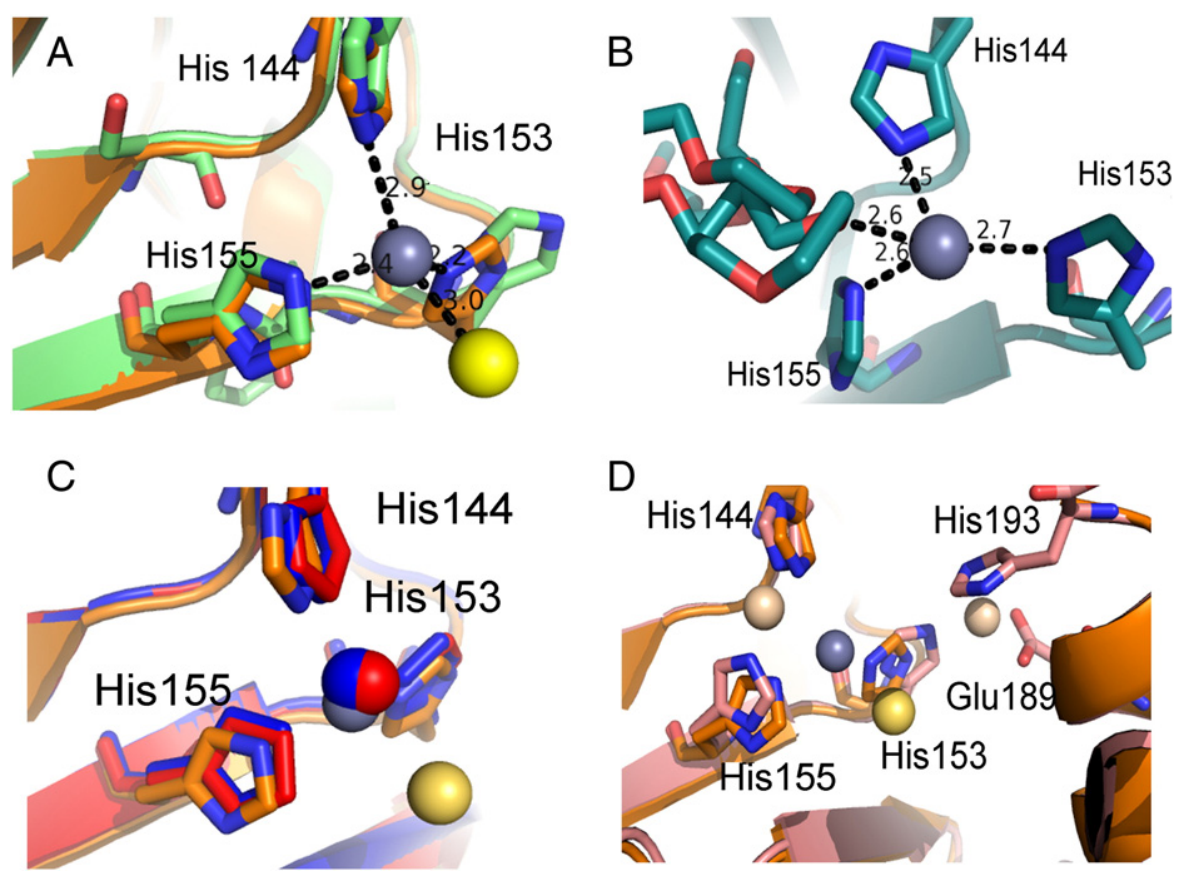

Fig. 2. Zn(II) binding site of S. enterica ZinT. In (A), superimposed binding site in metal-free SeZinT (green) and Zn(II)-SeZinT (orange). The coordinating residues and the distances from the metal are indicated. Zn(II) is colored gray and the coordinating water molecule yellow. In (B), binding site in Zn(II)-SeZinT-PEG. The coordinating residues, the PEG molecule and the distances from the metal are indicated. $\mathrm{Zn}$ (II) is colored gray. The figure is rotated about $90^{\circ}$ around His144 with respect to (A). In (C), superimposed binding site in Cd(II)-EcZinT, in red, Ni(II)-EcZinT, in blue, and in Zn(II)-SeZinT, in orange. Zn(II) is depicted in gray, Ni(II) in blue and Cd(II) in red. In (D), superimposed Zn(II) binding site of Zn(II)-EcZinT, in pink, and $\mathrm{Zn}(\mathrm{II})-$ SeZinT, in orange.

metal than MagFura2 $\left(\mathrm{K}_{\mathrm{D}}<20 \mathrm{nM}\right)$ and a second site of affinity in the micromolar range. A similar situation has been described for the two Zn(II) binding sites in E. coli ZnuA [19].

\subsection{SeZnuA-SeZinT interaction}

Gel filtration experiments by Petrarca et al. [10] reported that SeZinT and SeZnuA do not interact when metal-free, but give rise to a 1:1 complex in the presence of $\mathrm{Zn}(\mathrm{II})$. To gain further information on the conditions required for complex formation, the SeZinT-SeZnuA system was analyzed by sedimentation velocity in $20 \mathrm{mM}$ HEPES, $10 \mathrm{mM} \mathrm{NaCl}, \mathrm{pH} 7.5$ (Table 2). A 1:1 mixture (on a molar basis) of metal-free SeZnuA and SeZinT sediments at an intermediate velocity

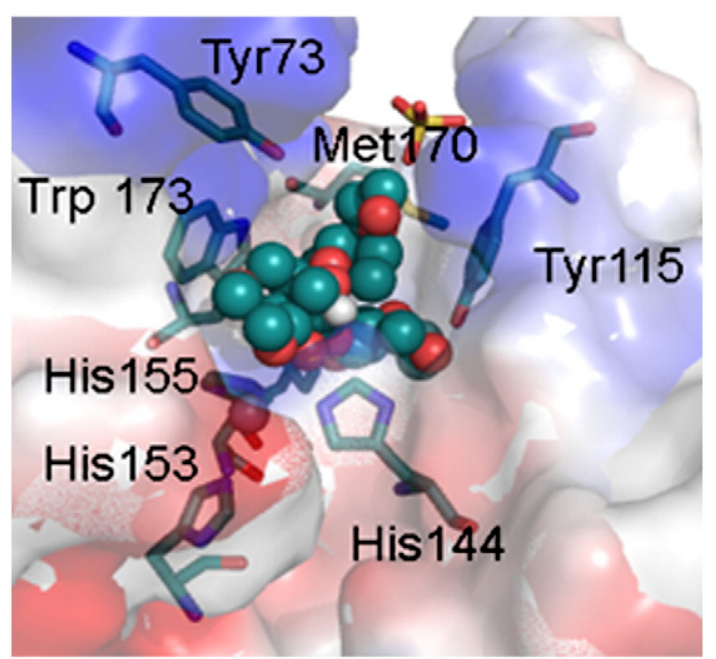

Fig. 3. Electrostatic surface and $\mathrm{Zn}$ (II) binding cavity in Zn(II)-SeZinT-PEG. The PEG molecule is represented as spheres. The residues interacting with PEG and the three $\mathrm{Zn}$ (II) coordinating histidines are represented as sticks. $\left(\mathrm{s}_{20, \mathrm{w}}=2.5 \mathrm{~S}\right)$ relative to the isolated proteins indicating that no interaction takes place in accordance with the Petrarca et al. data [10]. When the respective high affinity $\mathrm{Zn}$ (II) binding sites are saturated, SeZnuA and SeZinT sediment with an $\mathrm{s}_{20, w}$ value of $3.2 \mathrm{~S}$, consistent with formation of a 1:1 SeZnuA-SeZinT complex. To establish the dependence of complex formation on the metallation state of the two partner proteins, 1:1 molar mixtures were analyzed in which only one protein contained $\mathrm{Zn}$ (II). Importantly, when $\mathrm{Zn}$ (II)-SeZinT is mixed with apo-SeZnuA, the $s_{20, w}$ value (3.15S) points to formation of a 1:1 complex. In contrast, no interaction takes place when apo-SeZinT is mixed with SeZnuA containing one $\mathrm{Zn}(\mathrm{II}) /$ molecule so as to saturate the high affinity binding site $\left(s_{20, w}=2.60 \mathrm{~S}\right)$. It follows that formation of the SeZinT-SeZnuA complex is governed by the metallation state of SeZinT.

Many attempts have been made to obtain X-ray quality crystals of the SeZinT-SeZnuA complex. The complex has been isolated, purified by gel chromatography [10] and crystallized in the absence and in the presence of added $\mathrm{Zn}(\mathrm{II})$. More than 600 crystallization conditions have been explored with a high-throughput screening method using a crystallization robot. In the presence of added Zn(II), crystals diffracting only at very low resolution were obtained. Therefore, structural information on the mode of interaction between SeZinT and SeZnuA was gained by means of SAXS experiments on the purified complex.

The scattering curves computed from different dilutions in the range 0.17 to $5.0 \mathrm{mg} / \mathrm{ml}$ showed significant concentration dependency below $2.5 \mathrm{mg} / \mathrm{ml}$, suggesting the occurrence of dissociation. Hence, only the curves between 2.5 and $5 \mathrm{mg} / \mathrm{ml}$ were used for the analysis that yielded the overall parameters presented in Table 3. The $P(r)$ function shows a bell shape typical for globular or slighlty elongated proteins and yields a $D_{\max }$ of $\sim 85 \AA$ (Fig. $5 \mathrm{~A}$ ). Ab initio model reconstruction using DAMMIF/DAMAVER (NSD $=0.628 \pm 0.05)$ yields an estimated molecular mass of $\sim 38 \mathrm{kDa}$. This value agrees with other independent molecular mass estimations based on the Porod volume $(\sim 37 \mathrm{kDa})$ as well as on the forward scattering $I(0)(\sim 43 \mathrm{kDa})$, whereas the expected value of the SeZinT-SeZnuA complex is $53.2 \mathrm{kDa}$. A molecular mass 

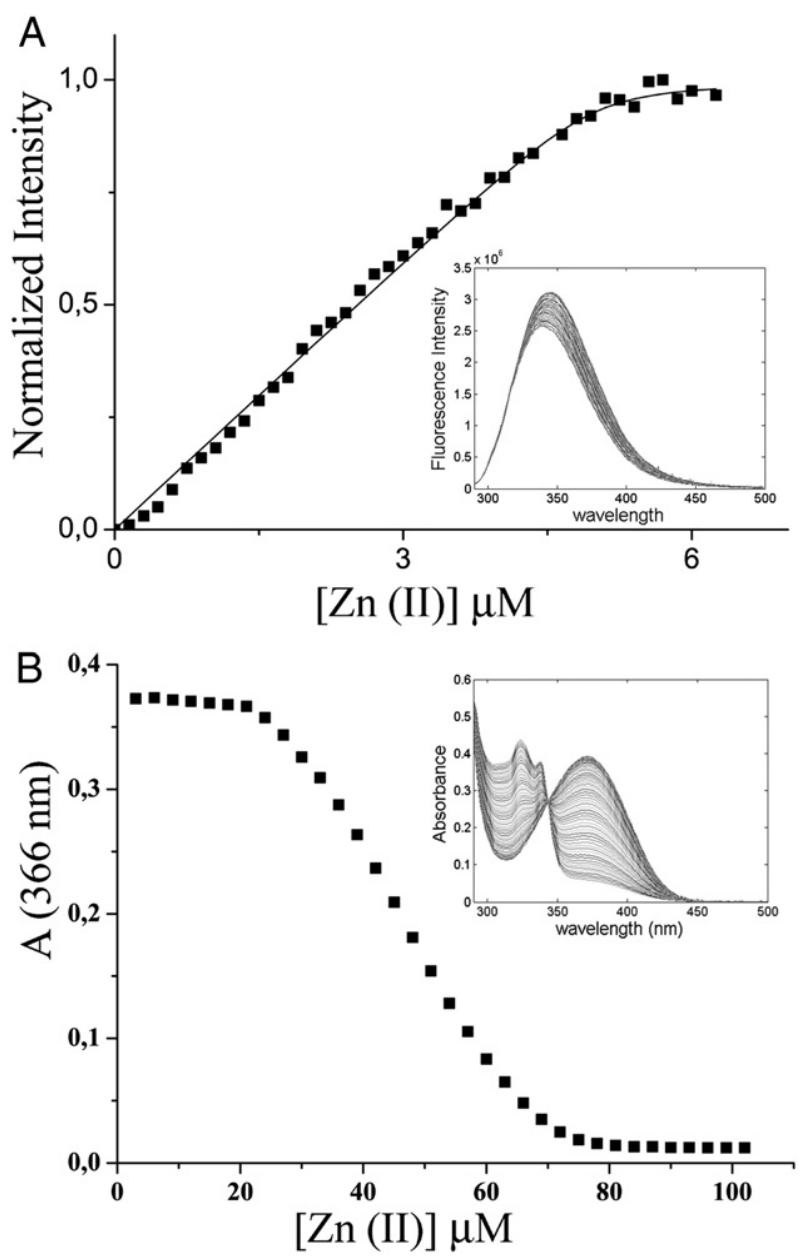

Fig. 4. Determination of the affinity for $\mathrm{Zn}$ (II) of S. enterica ZinT (A) and S. enterica ZnuA (B). In (A), fluorescence titration of SeZinT with Zn(II). Experimental data expressed as $\mathrm{I}-\mathrm{I}_{\max } / I_{\max }-\mathrm{I}_{\min }$ and plotted as a function of the total zinc concentration added. I is the fluorescence intensity at $340 \mathrm{~nm}, I_{\max }$ and $I_{\min }$ are, respectively, the maximum and minimum values measured during the titration. The continuous line represents the fit to the data yielding a $K_{D}$ value of $22 \pm 2 \mathrm{nM}$. In (B), titration of SeZnuA with Zn(II) in the presence of the indicator Mag-Fura-2. The absorbance of the indicator at $360 \mathrm{~nm}$ is plotted as a function of the total zinc concentration added. For details see under Material and methods.

value of $38-40 \mathrm{kD}$ can be accounted for by assuming that a finite equilibrium is established between the SeZinT-SeZnuA complex and the two isolated proteins. In particular, at the protein concentrations used for the analysis (4.7-9.4 $\left.\times 10^{-5} \mathrm{M}\right)$, the experimental molecular mass is obtained by assuming that SeZinT-SeZnuA and the isolated proteins are in a molar ratio of 2:1:1. On this basis, the value of the equilibrium constant, $\mathrm{K}_{\mathrm{D}}$, is around $10^{-5} \mathrm{M}$.

Table 2

Sedimentation velocity experiments on SeZinT and SeZnuA and their equimolar mixtures in their apo- and $\mathrm{Zn}(\mathrm{II})$-bound forms.

\begin{tabular}{ll}
\hline Protein & $\mathrm{s}_{20, \mathrm{w}}(\mathrm{S})$ \\
\hline Zn(II)-SeZnuA & 2.70 \\
Apo-SeZnuA & 2.70 \\
Zn(II)-SeZinT & 2.40 \\
Apo-SeZinT & 2.40 \\
Apo-SeZinT + apo-SeZnuA & 2.50 \\
Zn(II)-SeZinT + Zn(II)-SeZnuA & 3.20 \\
Zn(II)-SeZinT + apo-SeZnuA & 3.15 \\
Apo-SeZinT + Zn(II)-SeZnuA & 2.50 \\
Zn(II)-SeZinT + Zn(II)-SeZnuA $\Delta 118-141$ & 2.70 \\
\hline
\end{tabular}

The $s_{20, w}$ values represent the average of at least two experiments.
Table 3

Data collection and SAXS-derived parameters for the SeZinT-SeZnuA complex.

\begin{tabular}{ll}
\hline Data-collection parameters & \\
Instrument (detector) & PILATUS $1 \mathrm{M}$ pixel \\
& $\left(67 \times 420 \mathrm{~mm}^{2}\right)$ \\
Beam geometry & $0.7 \times 0.7 \mathrm{~mm}^{2}$ \\
Wavelength $(\AA)$ & 0.931 \\
$s$ range $\left(\mathrm{nm}^{-1}\right)$ & $0.05-4.5$ \\
Exposure time $(\mathrm{s})$ & 1 \\
Concentration range $\left(\mathrm{mg} \mathrm{ml}^{-1}\right)$ & $2.5-5$ \\
Temperature $(\mathrm{K})$ & 277.15 \\
Structural parameters & \\
$\left.I(0)(\mathrm{cm})^{-1}\right)[$ from $P(r)]$ & 45.550 \\
$R_{g}($ nm) $[$ from $P(r)]$ & $2.5 \pm 0.2$ \\
$\left.I(0)(\mathrm{cm})^{-1}\right)$ [from Guinier approximation] & 45.524 \\
$R_{g}($ nm) [from Guinier approximation] & $2.5 \pm 0.2$ \\
$D_{\text {max }}(\mathrm{nm})$ & $8.5 \pm 0.5$ \\
Porod volume estimate $\left(\AA^{3}\right)$ & $55 \pm 5$ \\
Dammif excluded volume $\left(\AA^{3}\right)$ & $76.4 \pm 5$ \\
Molecular-mass determination & \\
Molecular mass $M_{\mathrm{r}}(\mathrm{kDa})[$ from Porod invariant] & $37 \pm 5$ \\
Molecular mass $M_{\mathrm{r}}(\mathrm{kDa})$ [from excluded volume] & $38 \pm 5$ \\
Molecular mass $M_{\mathrm{r}}(\mathrm{kDa})[$ from $I(0)$ ] & $43 \pm 10$ \\
Software employed & \\
Primary data reduction & PIPELINE \\
Data processing & PRIMUS \\
Ab initio analysis & DAMMIF \\
Validation and averaging & DAMAVER \\
Rigid-body modeling & MASSHA \\
Computation of model intensities & CRYSOL \\
Three-dimensional representations & VMD \\
&
\end{tabular}

Lastly, quaternary structure of the SeZnuA-SeZinT complex derived from rigid body modeling of SeZinT (PDB code: 4ARH) and SeZnuA (PDB code: $2 \mathrm{XQV}$ ) and shown in Fig. 5A has the lowest discrepancy $(\chi=1.148)$ relative to the experimental data and a full compatibility with the $a b$ initio reconstruction (Fig. 5B). The calculated molecular envelope in Fig. 5B displays an ellipsoidal shape that fits well with the formation of a 1:1 complex between the two proteins. In turn, the model depicted in Fig. 5C indicates that the $\mathrm{Zn}$ (II) binding sites of both proteins face the complex interface and that the His-rich loop is keyed in the ZinT cavity between the calyx and the helical domain in a similar position as the PEG molecule (Fig. 5C). The observation that the $\mathrm{Zn}(\mathrm{II})-$ SeZnuA mutant devoid of the His-rich 118-141 loop (Zn(II)-SeZnuA $\Delta 118$-141) does not form a stable complex with (Zn)-SeZinT (Table 2) validates this indication.

\section{Discussion}

The multiplicity of physico-chemical techniques employed to characterize SeZinT reveals key structural features that are relevant to the role this protein plays in the management of periplasmic $\mathrm{Zn}$ (II) in addition to the major player, the high affinity uptake protein SeZnuA.

Three different X-ray SeZinT structures were solved, namely the apoprotein structure, the first available one, the $\mathrm{Zn}(\mathrm{II})$-bound form, and a further $\mathrm{Zn}(\mathrm{II})$-bound structure of likely physiological relevance that contains a PEG molecule. SeZinT displays the same two-domain architecture of EcZinT, as expected on the basis of the high sequence identity (Fig. 1) and likewise possesses one high affinity Zn(II) binding site, located at the end of the hydrophobic cavity formed between the calyx and the helical domain. In SeZinT, $\mathrm{Zn}(\mathrm{II})$ is bound in the same position as $\mathrm{Cd}(\mathrm{II})$ and $\mathrm{Ni}(\mathrm{II})$ in EcZinT [16]. However, the $\mathrm{Zn}(\mathrm{II})$ coordination differs. In SeZinT, $\mathrm{Zn}(\mathrm{II})$ is bound with tetrahedral coordination by three histidine residues from strands $F$ and $G$ of the calyx domain: His153 and His155 placed at a canonical coordination distance from the metal (2.2 and $2.4 \AA$ ), and His 144 at about $3.0 \AA$ from $\mathrm{Zn}(\mathrm{II})$. The fourth ligand, an oxygen atom, is provided by a water molecule. The binding of $\mathrm{Zn}$ (II) causes only slight movements limited to the coordinating histidine ligands; in particular His153 is shifted by $1.9 \AA$ A toward the cavity, suggesting that this residue may participate in 
the $\mathrm{Zn}(\mathrm{II})$ management process. The PEG-Zn(II)SeZinT structure, as alluded to above, is of special interest as it shows that the $\mathrm{Zn}$ (II) binding cavity between the calyx and the helical domain can harbor a long, single-chain polymer (Fig. 3). In a functional context, this can be envisaged to be part of the SeZnuA His-rich loop in accord with the SAXS-derived model of the SeZint-SeZnuA complex. In the model, the

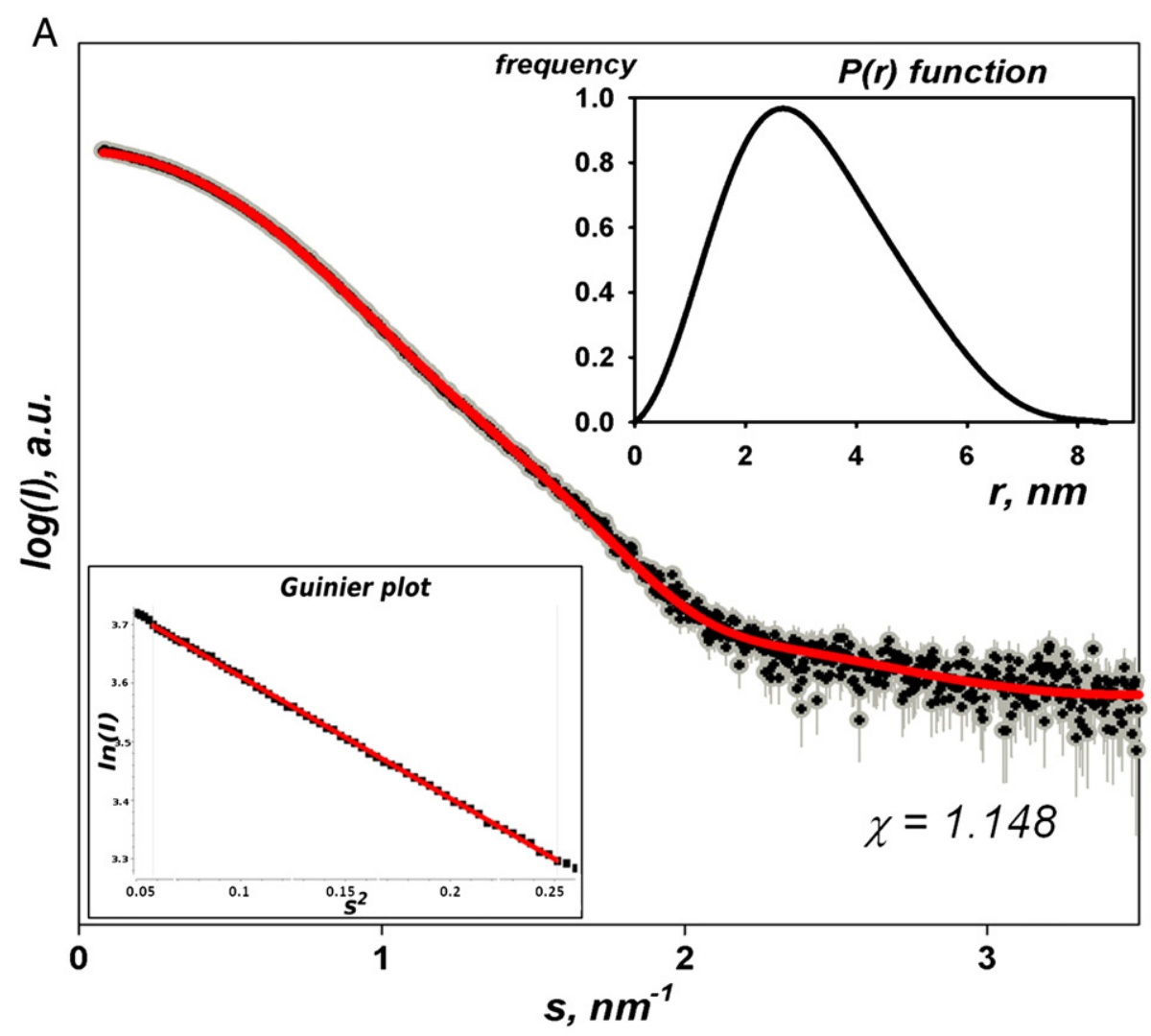

B

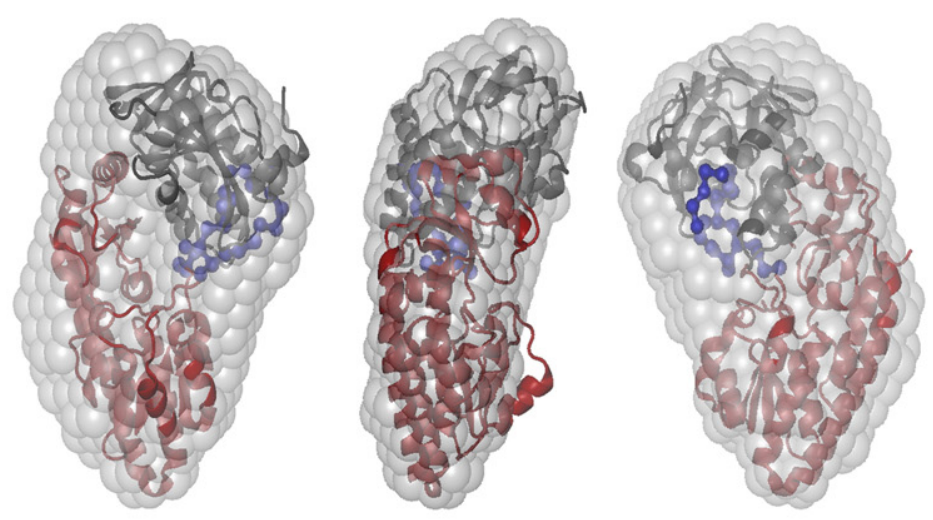

C

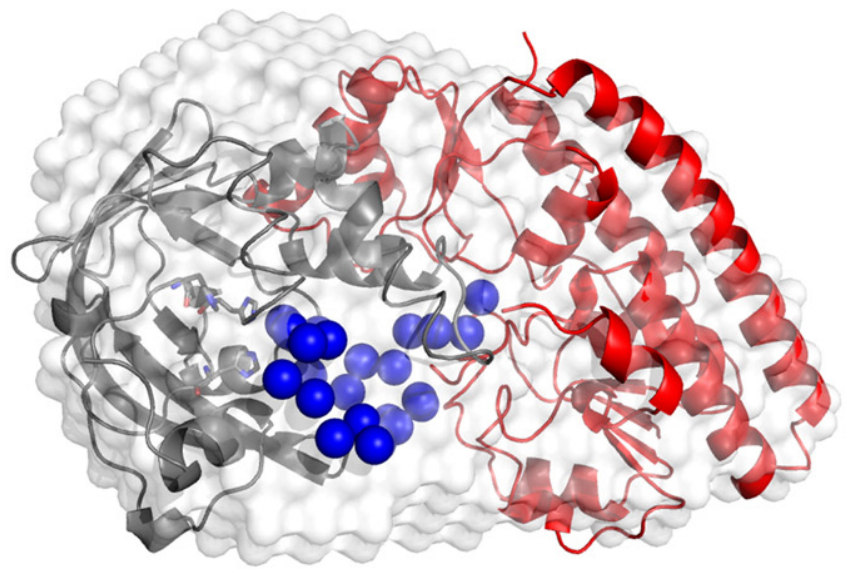


$\mathrm{Zn}$ (II) binding sites of the two proteins are juxtaposed and the ZnuA His-rich loop enters the SeZinT cavity between the calyx and the helical domain, just like the PEG molecule (Fig. 5C). This picture can be expanded to encompass the relative affinities of SeZint and SeZnuA for $\mathrm{Zn}(\mathrm{II})$. Based on the respective titration curves (Fig. 4A and B), SeZinT binds one $\mathrm{Zn}(\mathrm{II})$ with high affinity $\left(\mathrm{K}_{\mathrm{D}} 22 \pm 2 \mathrm{nM}\right)$, whereas SeZnuA binds two $\mathrm{Zn}(\mathrm{II})$ with significantly different affinity. The first site is characterized by a higher affinity for $\mathrm{Zn}$ (II) than the indicator MagFura2 $\left(K_{D}<20 n M\right)$. The affinity of the second site can be estimated to lie in the micromolar range. Titrations of SeZnuA bound to a fluorescent probe [46] likewise pointed to the presence of two $\mathrm{Zn}$ (II) binding sites. Their analysis yielded a $K_{D} \sim 1 \mu \mathrm{M}$ for the low affinity site, but did not allow measurement of the $K_{D}$ value pertaining to the high affinity one. The SeZnuA structures solved by Ilari et al. [13] suggest that the low affinity site is likely to be located on the His-rich loop.

The studies on Salmonella indicate that SeZinT transfers Zn(II) to SeZnuA and in so doing acts as an accessory member of the ZnuABC transport system $[10,11]$. This contention requires that SeZinT has a lower affinity for $\mathrm{Zn}(\mathrm{II})$ than $\mathrm{ZnuA}$ and that the two proteins form a complex solely when $\mathrm{Zn}(\mathrm{II})$ is bound to SeZinT. The affinity data just discussed and those on formation of the SeZinT-SeZnuA complex (Table 2) show that both requirements are met. The SAXS experiments add information on the stability of the complex. The estimated molecular mass, using both the excluded and the Porod volume, is $38-40 \mathrm{kDa}$, as compared to the calculated value of $53 \mathrm{kDa}$. This difference can be accounted for by assuming that the SeZnuA-SeZinT complex and the two partner proteins are in a 2:1:1 ratio, when the protein concentration is $9.0 \times 10^{-5} \mathrm{M}$. This finding is consistent with an affinity constant of about $10^{5} \mathrm{M}^{-1}$. It is worth recalling that the gel filtration experiments by Petrarca et al. [10] likewise indicated that the complex is in equilibrium with SeZinT and SeZnuA, but did not estimate the equilibrium constant. The SAXS data also provide information on the structural relationship between the two proteins in the complex. The model with the lowest discrepancy relative to the experimental data (Fig. 5C) indicates that the $\mathrm{Zn}$ (II) binding sites of both proteins face each other at the complex interface. It appears therefore that SeZinT and SeZnuA are in a structural relationship that allows $\mathrm{Zn}$ (II) to be transferred from $\mathrm{Zn}$ (II)SeZinT to SeZnuA, likely via the His-rich loop.

One may ask why Salmonella expresses ZinT since binding of periplasmic $\mathrm{Zn}$ (II) to ZnuA would be favored thermodynamically. It is well established [2] that the thermodynamics of metal binding in vitro does not describe fully the mechanisms operating in bacterial cells to ensure that each metallo-protein acquires the correct metal. On this basis, the presence of two structurally distinct periplasmic metal binding transporters (SeZnuA and SeZinT) can be expected to be more advantageous than increasing the concentration of a single one (SeZnuA). Thereby the bacterium can increase the ability to obtain $\mathrm{Zn}$ (II) from the surface of different proteins, where the metal is known to bind tightly in a rather unspecific manner. It is worth noting that recent studies have shown that the production of multiple proteins involved in zinc uptake is not limited to bacteria expressing ZinT. For example, Listeria monocytogenes expresses two ABC-type Zinc importers, both contributing to full virulence [47], while in Streptococcus pneumoniae the zinc importer AdcAII (a ZnuA homologue) can form a complex with the zinc-binding surface protein PhtD, suggesting that this interaction contributes to the efficiency of the zinc uptake mechanism [48].

In conclusion, the present data contribute significantly to the understanding of the periplasmic zinc transport mechanism mediated by the ZnuABC ATP binding cassette in Gram-negative bacteria. They lend support to the hypothesis of Petrarca et al. [10] that SeZinT binds
$\mathrm{Zn}(\mathrm{II})$ in the periplasmic space and contributes to metal transport by transferring the metal to SeZnuA that delivers it to ZnuB. Consequently, SeZinT can be considered an accessory component of the ZnuABC transporter that enhances the ability of ZnuA to recruit Zn(II) under conditions characterized by very low metal availability like those encountered by $S$. enterica within the infected host.

\section{Acknowledgements}

The authors gratefully acknowledge a grant from Fondazione Roma and funding from the European Community's Seventh Framework Programme (FP7/2007-2013) under BioStruct-X (grant agreement $\mathrm{N}^{\circ}$ 283570) and Bag Project 1223.8. They thank HZB (Helmholtz Zentrum Berlin) for allocation of synchrotron radiation beam-time and the European Synchrotron Radiation Facility (ESRF) for providing synchrotron radiation for the SAXS experiments at beamline BM29. F.A. was a recipient of a fellowship from Fondazione Roma. The authors thank Dr. Annarita Fiorillo for the SAXS mearurements.

\section{References}

[1] H. Irving, R.J.P. Williams, Order of stability of metal complexes, Nature 162 (1948) $746-747$.

[2] K.J. Waldron, N.J. Robinson, How do bacterial cells ensure that metalloproteins get the correct metal? Nat. Rev. Microbiol. 7 (2009) 25-35.

[3] C.E. Outten, F.W. Outten, T.V. O'Halloran, DNA distortion mechanism for transcriptional activation by ZntR, a Zn(II)-responsive MerR homologue in Escherichia coli, J. Biol. Chem. 274 (1999) 37517-37524.

[4] D. Wang, T.K. Hurst, R.B. Thompson, C.A. Fierke, Genetically encoded ratiometric biosensors to measure intracellular exchangeable zinc in Escherichia coli, J. Biomed. Opt. 16 (2011) 087011

[5] K. Hantke, Bacterial zinc uptake \& regulators, Curr. Opin. Microbiol. 8 (2005) 196-202.

[6] E.M. Panina, A.A. Mironov, M.S. Gelfand, Comparative genomics of bacterial zinc regulons: enhanced ion transport, pathogenesis, and rearrangement of ribosomal proteins, Proc. Natl. Acad. Sci. 100 (2003) 9912-9917.

[7] P. Ferianc, A. Farewell, T. Nystrom, The cadmium-stress stimulon of Escherichia coli K-12, Microbiology 144 (1998) 1045-1050.

[8] C.J. Kershaw, N.L. Brown, J.L. Hobman, Zinc dependence of $\operatorname{zinT}$ (yodA) mutants and binding of zinc, cadmium and mercury by ZinT, Biochem. Biophys. Res. Commun. 364 (2007) 66-71.

[9] A.I. Graham, S. Hunt, S.L. Stokes, N. Bramall, J. Bunch, A.G. Cox, C.W. McLeod, R.K. Poole, Severe zinc depletion of Escherichia coli: roles for high affinity zinc binding by Zint, zinc transport and zinc-independent proteins, J. Biol. Chem. 284 (2009) 18377-18389.

[10] P. Petrarca, S. Ammendola, P. Pasquali, A. Battistoni, The Zur-regulated ZinT protein is an auxiliary component of the high affinity ZnuABC zinc transporter that maximizes metal recruitment during severe zinc shortage, J. Bacteriol. 192 (2010) 1553-1564.

[11] R. Gabbianelli, R. Scotti, S. Ammendola, P. Petrarca, L. Nicolini, A. Battistoni, Role of ZnuABC and ZinT in Escherichia coli 0157:H7 zinc acquisition and interaction with epithelial cells, BMC Microbiol. 11 (2011) 36-47.

[12] A. Dintilhac, G. Alloing, C. Granadel, J.P. Claverys, Competence and virulence of Streptococcus pneumoniae: Adc and PsaA mutants exhibit a requirement for $\mathrm{Zn}$ and Mn resulting from inactivation of putative $\mathrm{ABC}$ metal permeases, Mol. Microbiol. 25 (1997) 727-739.

[13] A. Ilari, F. Alaleona, P. Petrarca, A. Battistoni, E. Chiancone, The X-ray structure of the zinc transporter ZnuA from Salmonella enterica discloses a unique triad of zinc-coordinating histidines, J. Mol. Biol. 409 (2011) 630-641.

[14] M. Falconi, F. Oteri, S. Di Palma, A. Pandey, A. Battistoni, A. Desideri, Structuraldynamical investigation of the ZnuA histidine-rich loop: involvement in zinc management and transport, J. Comput. Aided Mol. Des. 25 (2011) 181-194.

[15] S. Ammendola, P. Pasquali, C. Pistoia, P. Petrucci, P. Petrarca, G. Rotilio, A. Battistoni, The high affinity $\mathrm{Zn}^{2+}$ uptake system $\mathrm{ZnuABC}$ is required for bacterial zinc homeostasis in intracellular environments and contributes to virulence of Salmonella enterica, Infect. Immun. 75 (2007) 5867-5876.

[16] G. David, K. Blondeau, M. Schiltz, S. Penel, A. Lewit-Bentley, YodA from Escherichia coli is a metal-binding, lipocalin-like protein, J. Biol. Chem. 278 (2003) 43728-43735.

[17] B.R. Chandra, M. Yogavel, A. Sharma, Structural analysis of ABC-family periplasmic zinc binding protein provides new insights into mechanism of ligand uptake and release, J. Mol. Biol. 367 (2007) 970-987.

Fig. 5. SAXS analysis for the SeZnuA-SeZinT complex. In (A), experimental SAXS intensity profiles (logarithmic) for the SeZnuA-SeZinT complex (black dot) vs. CRYSOL computed theoretical scattering (red line). The figure also shows the linearity of the Guinier region as well as the derived pair-distance distribution function $P(r)$. In (B), SeZnuA-SeZinT interaction as derived from rigid body modeling. SeZnuA (red, PDB code: $2 \mathrm{XQV}$ ) and SeZinT (black, PDB code: 4ARH) assemble into a rather globular complex fully compatible with the ab initio shape computed from experimental data only using DAMMIF/DAMAVER (gray). The missing loop SeZnuA $\triangle 118-141$ (blue) was reconstructed using BUNCH. ZnuA is colored red, the reconstructed His rich loop is colored blue and ZinT is colored in gray. In (C), blow-up of the Se-ZnuA-SeZinT complex interface. ZnuA is colored red, the reconstructed His rich loop is colored blue and ZinT is colored in gray. 
[18] H. Li, G. Jogl, Crystal structure of the zinc-binding transport protein ZnuA from Escherichia coli reveals an unexpected variation in metal coordination, J. Mol. Biol. 368 (2007) 1358-1366.

[19] L.A. Yatsunyk, J.A. Easton, L.R. Kim, S.A. Sugarbaker, B. Bennett, R.M. Breece, I.I. Vorontsov, D.L. Tierney, M.W. Crowder, A.C. Rosenzweig, Structure and metal binding properties of ZnuA, a periplasmic zinc transporter from Escherichia coli, J. Biol. Inorg. Chem. 13 (2008) 271-288.

[20] S. Banerjee, B. Wei, M.B. Pakrasi, H.B. Pakrasi, T.J. Smith, Structural determinants of metal specificity in the zinc transport proteins ZnuA from Synechocystis 6803, J. Mol. Biol. 333 (2003) 1061-1069.

[21] U. Müller, N. Darowski, M.R. Fuchs, R. Förster, M. Hellmig, K.S. Paithankar, S. Pühringer M. Steffien, G. Zocher, M.S. Weiss, Facilities for macromolecular crystallography at the Helmholtz-Zentrum Berlin, J. Synchrotron Radiat. 19 (2012) 442-449.

[22] Z. Otwinowski, W. Minor, Processing of X-ray diffraction data collected in oscillation mode, Methods Enzymol. 276 (1997) 307-332.

[23] A.G.W. Leslie, H.R. Powell, Processing diffraction data with MOSFLM, in: R. Read, J.L. Sussman (Eds.), Evolving Methods for Macromolecular Crystallography, The Netherlands NATO Series II, 245, Springer, Dordrecht, 2007, pp. 41-51.

[24] M.A. Larkin, G. Blackshields, N.P. Brown, R. Chenna, P.A. McGettigan, H. McWilliam, F. Valentin, I.M. Wallace, A. Wilm, R. Lopez, J.D. Thompson, T.J. Gibson, D.G. Higgins, ClustalW and ClustalX version 2, Bioinformatics 23 (2007) 2947-2948.

[25] A. Vagin, A. Teplyakov, MOLREP: an automated program for molecular replacement J. Appl. Crystallogr. 30 (1997) 1022-1025.

[26] M.D. Winn, C.C. Ballard, K.D. Cowtan, E.J. Dodson, P. Emsley, P.R. Evans, R.M. Keegan, E.B. Krissinel, A.G.W. Leslie, A. McCoy, S.J. McNicholas, G.N. Murshudov, N.S. Pannu, E.A. Potterton, H.R. Powell, R.J. Read, A. Vagin, K.S. Wilson, Overview of the CCP4 suite and current developments, Acta Crystallogr. D67 (2011) 235-242.

[27] G.N. Murshudov, A.A. Vagin, E.J. Dodson, Refinement of macromolecular structures by the maximum-likelihood method, Acta Crystallogr. D Biol. Crystallogr. 53 (1997) 240-255.

[28] P. Emsley, K. Cowtan, Coot: model-building tools for molecular graphics, Acta Crystallogr. D Biol. Crystallogr. 60 (2004) 2126-2132.

[29] R.A. Laskowski, M.W. MacArthur, D.S. Moss, J.M. Thornton, PROCHECK: a program to check the stereochemical quality of protein structures, J. Appl. Crystallogr. 26 (1993) 283-291.

[30] G.K. Walkup, B. Imperiali, Design and evaluation of a peptidyl fluorescent chemosensor for divalent zinc, J. Am. Chem. Soc. 119 (1996) 3443-3450.

[31] K.E. Dineley, L.M. Malaiyandi, I.J. Reynolds, A reevaluation of neuronal zinc measurements: artifacts associated with high intracellular dye concentration, Mol. Pharmacol. 62 (2002) 618-627.

[32] P. Pernot, P. Theveneau, T. Giraud, R. Nogueira Fernandes, D. Nurizzo, D. Spruce, J. Surr S. McSweeney, A. Round, F. Felisaz, L. Foedinger, A. Gobbo, J. Huet, C. Villard, F.P. Cipriani, New beamline dedicated to solution scattering from biological macromolecules at the ESRF, J. Phys. Conf. Ser. 247 (2010) 012009.

[33] A.R. Round, D. Franke, S. Moritz, R. Huchler, M. Fritsche, D. Malthan, R. Klaering, D.I. Svergun, M. Roessle, Automated sample-changing robot for solution scattering experiments at the EMBL Hamburg SAXS station X33, J. Appl. Crystallogr. 41 (2008) 913-917.

[34] A. Guinier, La diffraction des rayons X aux tres petits angles; application a l'etude de phénomènes ultramicroscopiques, J. Physiol. Paris 12 (1939) 161-237.

35] P.V. Konarev, V.V. Volkov, A.V. Sokolova, M.H.J. Koch, D.I. Svergun, PRIMUS: a Windows PC-based system for small-angle scattering data analysis, J. Appl. Crystallogr. 36 (2003) 1277-1282.

[36] M.V. Petoukhov, D. Franke, A.V. Shkumatov, G. Tria, A.G. Kikhney, M. Gajda, C. Gorba H.D.T. Mertens, P.V. Konarev, D.I. Svergun, New developments in the ATSAS program package for small-angle scattering data analysis, J. Appl. Crystallogr. 45 (2012) 342-350.

[37] D.I. Svergun, Determination of the regularization parameter in indirect-transform methods using perceptual criteria, J. Appl. Crystallogr. 25 (1992) 495-503.

[38] G. Porod, General theory, in: O. Glatter, O. Kratky (Eds.), Small Angle X-ray Scattering, Academic Press, London, 1982

[39] V.V. Volkov, D.I. Svergun, Uniqueness of ab initio shape determination in small-angle scattering, J. Appl. Crystallogr. 36 (2003) 860-864.

[40] E. Mylonas, D. Svergun, Accuracy of molecular mass determination of proteins in solution by small-angle X-ray scattering, J. Appl. Crystallogr. 40 (2007) 245-249.

[41] D. Franke, D.I. Svergun, DAMMIF, a program for rapid ab-initio shape determination in small-angle scattering, J. Appl. Crystallogr. 42 (2009) 342-346.

[42] P.V. Konarev, M.V. Petoukhov, D.I. Svergun, MASSHA - a graphic system for rigid body modelling of macromolecular complexes against solution scattering data, J. Appl. Crystallogr. 34 (2001) 527-532.

[43] M.V. Petoukhov, D.I. Svergun, Global rigid body modelling of macromolecular complexes against small-angle scattering data, Biophys. J. 89 (2005) 1237-1250.

[44] D.I. Svergun, C. Barberato, M.H.J. Koch, CRYSOL - a program to evaluate X-ray solution scattering of biological macromolecules from atomic coordinates, J. Appl. Crystallogr. 28 (1995) 768-773.

[45] M. Kozin, D. Svergun, Automated matching of high- and low-resolution structural models, J. Appl. Crystallogr. 34 (2001) 33-41.

[46] L. Castelli, P. Stella, A. Petrarca, A. Battistoni, A. Desideri, M. Falconi, Zinc ion coordination as a modulating factor of the ZnuA histidine-rich loop flexibility: a molecular modeling and fluorescence spectroscopy study, Biochem. Biophys. Res. Commun. 430 (2013) 769-773

[47] D. Corbett, J. Wang, S. Schuler, G. Lopez-Castejon, S. Glenn, D. Brough, P.W. Andrew, J.S. Cavet, I.S. Roberts, Two zinc uptake systems contribute to the full virulence of Listeria monocytogenes during growth in vitro and in vivo, Infect. Immun. 80 (2012) $14-21$.

[48] E. Loisel, S. Chimalapati, C. Bougault, A. Imberty, B. Gallet, A.M. Di Guilmi, J. Brown, T. Vernet, C. Durmort, Biochemical characterization of the histidine triad protein PhtD as a cell surface zinc-binding protein of Pneumococcus, Biochemistry 50 (2011) 3551-3558.

[49] W.L. DeLano, The PyMOL Molecular Graphics System, DeLano Scientific, San Carlos, CA, 2002. 